\title{
A nested approach to the right to food: Food security, gender violence, and human rights
}

\author{
Kathleen P. Hunt * \\ Iowa State University
}

Review of Gender, Nutrition, and the Human Right to Adequate Food: An Inclusive Framework, edited by Anne C. Bellows, Flavio L. S. Valente, Stefanie Lemke, and María Daniela Núñez Burbano de Lara. (2016).

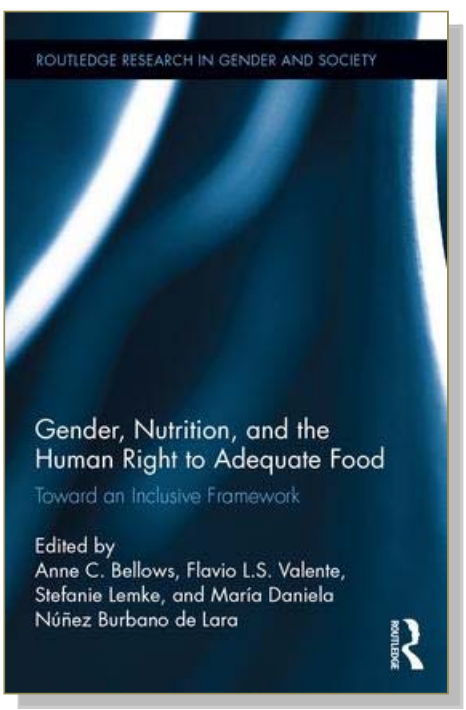

Published by Routledge in its Research in Gender and Society series. Available as hardcover; 472 pages. Publisher's website: https://www.routledge.com/GenderNutrition-and-the-Human-Right-to-Adequate-Food-Toward-an-Inclusive/BellowsValente-Lemke-Nunez-Burbano-de-Lara/p/book/9780415714457

Submitted October 1, 2016 / Published online December 12, 2016

Citation: Hunt, K. P. (2016). A nested approach to the right to food: Food security, gender violence, and human rights [Book review]. Journal of Agriculture, Food Systems, and Community Development, 7(1), 141-143. http://dx.doi.org/10.5304/jafscd.2016.071.008

Copyright (C) 2016 by New Leaf Associates, Inc.

1 and the Human Right to Adequate Food: An Inclusive Framework bring public policy, political economy, and gender equity together to create an inclusive framework for food system reform. Uniting human rights, gender discrimination, and food sovereignty, the book offers a comprehensive analysis of the complex intersections between food and nutritional justice, as well as structural poverty

\footnotetext{
* Dr. Kathleen P. Hunt is an assistant professor of agricultural communication in the Department of Agricultural Education and Studies at Iowa State University in Ames, Iowa. Areas of research interest are agro-environmental communication, political economy, and the discourse of food security. She can be contacted at kphunt@iastate.edu.
}

and violence. The text is a product of the collaborative effort between the Gender Nutrition Rights (GNR) university-based research group and two international nongovernmental organizations, FIAN International and the Geneva Infant Feeding Association (GIFA), as part of ongoing efforts to "contribute to the capacity and momentum for action and human rights enforceability through the full engagement and self-determination of all women and men in the pursuit of nutritional wellbeing, with human dignity" (p. xxix). Together, the analyses presented in Gender, Nutrition, and the Human Right to Adequate Food add necessary depth to the consideration of patterns in food insecurity and gender violence, barriers to the full realization 
of a human right to food, and structural disconnects in the theory and practice of gender security and nutritional access.

From the book's outset, inadequate food access and extreme poverty are inextricably linked to gender discrimination and violence. The food crisis of 2008 significantly affected millions of people in areas long familiar with hunger, malnutrition, and famine, often in high-risk and remote environments where women play key roles in household food provisioning and make up about $60 \%$ of the hungry and $70 \%$ of the poor (p. 1). That the most food-insecure populations are also those in which women and girls face greater disparities in social power illustrates the nested nature of food security and gender security. Indeed, structural inequalities across demographic markers such as status of livelihood, rural-urban location, ethnicity, and class are "consistently compounded by and manifested within gender discrimination" (p. xxxvi).

Bellows, de Lara, and Viana comprehensively review the evolution of human rights and food security approaches, frameworks, and policies in the first chapter, tracing the continuing struggle "over the future of the global governance of food and nutrition policy" (p. 2). Keeping track of the alphabet soup of government agencies, nongovernmental organizations, international conventions, and various resolutions and accords can be cumbersome; this unavoidable characteristic of human rights and international development illustrates the complexity, limitations, and need for continued advancement in these endeavors. While human rights and food security discourse and practice since the mid-20 th century have called for greater inclusion of women and a gender perspective, it is important to note that the food and nutrition status of women and girls has not realized significant improvement. Furthermore, even as particular human rights instruments have been designed to protect the rights of women and girls, instances of food and nutrition rights violations among women and girls have increased relative to men and boys. Pointing to the externalization of hunger in a neoliberal global economy, and the limited capability of those who suffer from hunger, structural violence "manifest $[s]$ discrimination between the hungry and the policy makers" (xxviii). The shift toward a human rights framework for food and nutrition security requires the recognition "of the universality and indivisibility of human rights," and that they "cannot be viewed independently from, for example, the human right to the highest attainable standard of health, or the human rights of women and children" (p. 25).

It is against this backdrop that the conditions impeding the progress of women's rights and food security are critiqued. In the second chapter, Bellows and de Lara introduce the means by which women's rights and nutrition have been isolated through the creation of legally binding international agreements. Analysis of the Universal Declaration of Human Rights (UDHR) and the International Covenant on Economic, Social and Cultural Rights (ICESCR) reveals the breakdowns in international policymaking that have structurally disconnected improvements in gender-based inequality and the human right to adequate food and nutrition. These authors make a compelling case for reframing the status of women and girls in institutional reforms from vulnerability to discrimination, noting that the former "may in fact contribute to sociocultural patterns of patronization and gender discrimination" (p. 59). Furthermore, the political economy of food production, coupled with the increased reliance on private-sector engagement in UN human rights efforts and public policy, have separated nutrition from food security-hence the intentional phrasing throughout this volume, the right to adequate food and nutrition — propping up the commoditization of agricultural products, and the medicalization of micronutrient supplementation (p. 72). Chapter 2 illustrates the paternalistic and neoliberal effects of food security policy and the implications thereof for reifying gender discrimination.

The remaining chapters unpack specific underexamined aspects of gender, nutrition, and food security. The correlation between women and girls' food-based work and gender violence is taken up in Chapter 3, in which Bellows and Jenderedijian trace the various forms of structural violenceincluding deleterious cultural dietary practices, restriction from public participation, and isolation from research —and institutional efforts for 
reform. Case studies are used to evidence what have often been perceived as abstract concepts, while also underscoring the need for addressing gender violence both at national and international levels, as is discussed in the latter half of the chapter. Lhotska, Scherbaum, and Bellows return to the importance of nutrition in Chapter 4, homing in on the role of childbearing and health across the lifespan. As yet another nested component of the gender security and food security equation, equitable nutrition is largely rendered invisible in policymaking efforts. Indeed, as these authors note, full realization of the right to adequate food and nutrition must account for the unique capacity of women to bear children and breastfeed. What they call the "entwined subjectivities of mother and child," or the dependency of a child's health from conception through infancy as influenced by a context of socioeconomic conditions and living environment, has yet to be fully embraced by human rights instruments (p. 164). From the angle of greater promotion of local agriculture and food systems in support of sustainable livelihoods, in Chapter 5 Lemke and Bellows critique the dominant market-based systems that promote international trade as the primary response to food insecurity and malnutrition. Synthesizing threads from the previous chapters-including the patronizing effects of extant food security policies and the problematic practice of medicalized food assistance - connections between the shortcomings of measures aimed to address malnutrition and the paternalistic polices that promote food and nutrition aid dependences are brought into sharp focus. Taken together, these analyses lay bare the nested nature of gender security and food security, and the need for an inclusive approach to the human right to adequate food and nutrition.

Balancing comprehensive and compelling examination of the limits of extant human rights and food-security frameworks, with clear and constructive pathways forward, can be difficult with a thesis as fundamental as that presented by this volume. To be sure, the nested nature of gender discrimination, neoliberal political economy, patronizing public policy and international aid efforts, food access, health across the lifespan, and local livelihoods is necessarily complex; the premise that gender security and food security are inextricably linked requires in-depth analysis. However, the degree to which each chapter painstakingly walks readers though various iterations of international policies, shifts in gendered practices over time, new vocabulary and concepts, and repeated calls to address barriers and provide more adequate and equitable support, often relegates recommendations to the final pages of any given chapter.

In the final chapter, Valente, Franco, and Montes bring the volume full circle in a presentation of a new conceptual framework for the human right to adequate food and nutrition. Summarizing the conditions, disconnects, and fragmentations presented in the preceding chapters, "the role of human rights in improving women's food and nutrition security and in reducing hunger and malnutrition" (p. 341) is at the center of the volume's conclusion. Uniting Amartya Sen's capability approach, food sovereignty, and principles of participatory governance, the human right to adequate food and nutrition goes beyond "mere access to food stuffs... [and] freedom from hunger," as is the parlance and practice of extant human rights and food security policy, to "encompass how societies organize to feed themselves adequately and sustainably, in a participatory way" (p. 355). The authors present a three-pronged approach to redefining and actualizing the human right to adequate food and nutrition, codifying specific obligations and provisions in the People's and Food Sovereignty Matrix (p. 369). The chapter concludes with implications for collaborations with social movements and recommendations for human rights reform and institutional coordination.

This well composed and far-reaching volume adds critical insight to the intersections of human rights, gender discrimination, and food sovereignty. Reflecting the composition and mission of the collaborative team from which this project is borne, this text is relevant across research-, theoretical-, and application-based efforts at food system reform and human rights advocacy and enforcement. Students of international development, political economy, food systems, and gender studies would benefit from the analyses and case studies herein. 